\title{
ОСНОВЫ ТЕОРИИ ПОИСКА РЕНТЫ
}

\author{
П.А. ЯНОВИЧ \\ аспирант Белорусского государственного университета \\ экономического факультета
}

\begin{abstract}
Аннотация
Различные трактовки ренты выделяют разные аспекты этой экономической категории. Первоначально категория рента рассматривалась как элемент микроэкономической теории. Затем теория ренты приобрела характер макроэкономической теории. В настоящее время существуют несколько подходов, определяющих природу рентных отношений. При этом необходимо рассматривать в совокупности рентные отношения и поиск прибыли.
\end{abstract}

Ключевые слова: рента, рентные отношения.

Abstract

Different interpretations of the rent distinguish various aspects of the economic category. Initially, the category of rent was regarded as an element of microeconomic theory. Then the theory of rent acquired the character of macroeconomic theory. Currently, there are several approaches that define the nature of rent relations. Herewith rent relations and the search for profit should be considered together.

Key words: rent, rent relations.

\section{ВВЕДЕНИЕ}

Поиск ренты - это деятельность, направленная на достижение определенных экономических выгод. Госсубсидии и государственное ограничение конкуренции часто становятся конкретными целями поиска ренты. Иногда вся получаемая путем поиска ренты прибыль расходуется в процессе обеспечения и поддержания необходимых для получения ренты привилегий. Это так называемые рентные доходы.

\section{РЕЗУЛЬТАТЫ И ИХ ОБСУЖДЕНИЕ}

В современной экономической теории под рентой понимается «разница между доходом фактора и минимальной суммой, необходимой для обеспечения этим фактором данного объема услуг» [1, с. 778]. 
В словаре Рутледжа по экономической теории она трактуется как «часть дохода редкого фактора производства, превышающая удерживающий доход и обусловленная редкостью фактора» [2, p.137].

Наличие ренты позволяет владельцу ресурсов искать варианты их наиболее эффективного размещения и использования, создает стимулы для инвестиций.

Один из основателей теории общественного выбора и поиска ренты это американский экономист Гордон Таллок.

Американский экономист Роберт Толлисон дает определение поиска ренты как «расход редких ресурсов ради захвата искусственно созданного трансферта» [3, p. 578]. Джеймс Макгилл Бьюкенен-младший характеризует термин “поиск ренты" как «описания поведения в институциональной среде, где индивидуальные усилия максимизировать ценность порождают общественные потери, а не прибавку для общества» [4, p.4]. Согласно Гордону Таллоку: «Поиск ренты: использование ресурсов с целью получения ренты, где рента проистекает из нечто такого, что имеет негативную общественную ценность» [5, p. 79]. В другой работе он отмечает, что «индивид, который инвестирует в нечто, что в действительности не улучшит производительность или же в действительности ее ухудшит, но таким образом повысит свой доход, поскольку это даст ему особое положение или монопольную власть, осуществляет поиск ренты»[6, p.17].

Во всех определениях присутствует указание на затраты, которые понесло общество, вместо выгод, которые оно могло бы иметь, в случае, если ресурсы, использованные на получение ренты, были бы применены производительно. Можно принять определение Роберта Толлисона и рассматривать поиск ренты как «затраты ресурсов ради трансферта» [7, р.26]. «Трансферт не меняет общее благосостояние. Если ради трансферта требуется затратить ресурсы, то тогда общество несет чистые потери в благосостоянии, а деятельность, обеспечивающая его получение, характеризуется как поиск ренты термином, в который в этом случае справедливо вкладывается негативный смысл»[8, с. 85]. Отсюда можно сделать вывод что, поиск прибыли имеет место тогда, когда размещение ресурсов ради получения ренты генерирует общественное благосостояние, а поиск ренты, когда размещение ресурсов ради той же цели генерирует потери общества.

Разграничение поиска ренты и поиска прибыли ставит вопрос о роли государства в обеспечении условий для поиска ренты.

К. Коулинг и Д. Мюллер предложили трактовку потерь от поиска ренты. По их определению «существующая в длительном периоде прибыль, в любом случае есть результат поиска ренты, независимо от того, 
обусловлены ли она государственным регулированием или факторами неценовой конкуренции». [9, pp. 727-748.]. Из расширенной трактовки поиска ренты можно сделать вывод о необходимости антимонопольной политики, особенно в тех случаях, когда фирмы несут расходы на такие формы неценовой конкуренции, как реклама или исследования [10, с. 126-128.].

Такие же взгляды отстаивал Дэвид Коландер, который включает «в потерю благосостояния от поиска ренты, затраты на возведение входных барьеров через дифференциацию продукции, рекламу, маркетинг и дизайн продукции». В эту же категорию были отнесены затраты на приобретение избыточных мощностей, временное использование стратегического ценообразования в целях предотвращения вхождения на рынок конкурентов и, в целом, установление таких условий на рынке факторов, которые оптимальны для утвердившихся на нем фирм, но не оптимальны для тех, кто потенциально готов на него войти [11, p. 201].

Таким образом, при рассмотренном подходе поиск ренты распространяется за пределы государственного регулирования. Исчезают различия между политическим лоббированием и конкуренцией.

Противоположный взгляд ограничивает поиск ренты сферой государственного регулирования. Неценовая конкуренция на рынке трактуется как динамический процесс, а не рыночное равновесие. Источниками поиска ренты и общественных потерь является неценовое конкурентное поведение и периодические прибыли. При этом государственное регулирование должно являться условием возникновения рентоориентированного поведения.

Государственное регулирование экономики создает административные барьеры и не позволяет рыночному распределению ресурсов, которое характерно для конкурентного рыночного механизма. Поиск ренты ведет к потерям общества. Эти потери ограничены ресурсами, вовлеченными в лоббирование интересов. «Обычно, пишет Роберт Толлисон, концепция поиска ренты применяется к случаям, когда государственное вмешательство в экономику ведет к созданию искусственных или изобретенных рент» [12, р. 508.].

В то же время, в литературе по проблемам поиска ренты, она может рассматриваться и как не связанная непосредственно с государственным регулированием. Например, Бьюкенен обратил внимание, что «борьба детей за родительское наследство может вести к потерям от поиска ренты внутри семьи» [13, pp. 71-85]. Пол Роберт Милгром и Деннис Робертсон исследуют поиск ренты внутри фирмы [14, с.23-24].

Вместе с тем понятие теории поиска ренты не сводится только к присутствию государства в рентных отношениях. Появление теории ренты 
также связано с вопросом о делении деятельности на производительную и непроизводительную, поскольку поиск ренты отнесен к непроизводительной деятельности. Современная теория прав собственности поставила под сомнение трактовку поиска ренты как непроизводительной деятельности, приносящей только чистые общественные потери.

В теории поиска ренты различие между производительным и непроизводительным использованием ресурсов было охарактеризовано в статье Михаэля Брукса, Бена Хейджры и Антона Лоуенберга как «воспоминание» об Адаме Смите и проведенном им различии между производительным и непроизводительным трудом. Критикуя определение поиска ренты как изначально непроизводительной деятельности, подчеркивается тот факт, что «различие между производительной и непроизводительной деятельностью имеет смысл только в рамках трудовой теории стоимости и не имеет смысла в теории ценности на основе субъективной полезности» [15, pp. 419-438].

Отождествление поиска ренты и непроизводительной деятельности наиболее ярко рассматривается в концепции «непосредственно непроизводительного поиска прибыли», которая противопоставляет себя развиваемой представителями виргинской школы теории поиска ренты [16, рр.15-25].

Попытка соединения теории прав собственности с теорией поиска ренты принадлежит Дэвиду Сиску [17, pp. 95-102.]. Он утверждал, что «поиск ренты может иметь как желательные, так и нежелательные последствия». В качестве «желательного» поиска ренты он ссылается на лоббирование прав собственности на общедоступные ресурсы, когда затраты на лоббирование компенсируются последующим эффективным использованием этих ресурсов [18, с.126-150]. «Нежелательный» поиск ренты, по Д. Сиску, характеризуется «недобровольными» трансфертами, то есть приобретение потребительского излишка в результате предоставленных государством монопольных привилегий. В отличие от Д. Сиска, Д. Бьюкенен считает, что «нежелательный» поиск ренты может иметь место и при наличии добровольных некомпенсированных трансфертов» $[19$, рр. 1-6].

Paul V. McNutt приходит к выводу, что при использовании подходов теории прав собственности для характеристики поиска ренты, «поиск ренты - это растрата до тех пор, пока не получена компенсация за этот трансферт» [20, pp. 44-46]. Если же имеет место добровольный и компенсированный трансферт ресурсов, то поиск ренты будет «желательным». Paul V. McNutt считает, что «если процесс закрепления ресурсов в собственность осуществляется через рентоориентированное поведение, характеристика последнего как растраты или блага для 
общества целиком зависит от того, получает ли донор (поставщик трансфертов) компенсацию или нет». «Нежелательный» поиск ренты появляется тогда, когда индивид или общество не получают компенсацию за трансферт ресурсов (причем не столь важно, добровольный он или недобровольный). Если поиск ренты закрепляет права собственности, но общество не выигрывает от такого закрепления (т.е. компенсация отсутствует или недостаточна), то поиск ренты является «нежелательным» [21, pp.161-162]. Такой компенсацией, по его мнению, может быть «ценность полученной информации о предпочтениях, которая выявляется только в результате различных проявлений рентоориентированного поведения. Если чистая выгода от затрат ресурсов на поиск ренты уравновешивается с ее общественными издержками, то в таком случае имеет смысл говорить об оптимальном уровне этих затрат» [21, p.164].

Активность в сфере распределения прав собственности, это есть деятельность по поиску ренты. Это вытекает из подхода к правам собственности, который отличается от подхода неоклассической теории. В неоклассической теории эти права не являются предметом изучения. В теории прав собственности, в рамках современного неоинституционализма, эти права формируются и распределяются в процессе взаимодействия экономических и политических агентов, причем важны не только формально закрепленные в конституции и законах права, но и неформальные нормы [22, р.40]. Поиск ренты - одна из форм такого взаимодействия.

Теория прав собственности ставит вопрос не только об общественных потерях от поиска ренты, но и об общественных выгодах от такого поведения. Она не дает отрицательной характеристики поиска ренты, как только расходы ресурсов в чистом виде, а предлагает каждый раз взвешивать потери и выгоды. Извлеченная рента может выглядеть как трансферт, переходящий от частных владельцев ренты в руки законодателей или бюрократии. Рассматривая потери общества от монополии, то такой подход к переходящей от потребителей монополисту части ренты потребителя впервые подверг сомнению Г. Таллок [23, рp.224-232]. Он показал, что «ради получения этого трансферта потенциальный монополист также затрачивает и реальные ресурсы, имеющие альтернативную стоимость. А она должна быть добавлена к традиционным расчетам потерь общества от монополизации. Аналогичным образом и переходящая от бизнеса политикам рента - не просто трансферт. Сам факт наличия угрозы изъятия ренты ведет к ряду потерь для общества. Во-первых, вероятность, что государство сможет снизить отдачу от капитала, естественным образом снижает стимулы фирм к инвестициям. В этом случае потеря общества теоретически может быть 
определена как разность между теми инвестициями, которые были бы сделаны в случае отсутствия политических угроз, и теми инвестициями, которые реально произведены. Во-вторых, угроза изъятия ренты ведет к перемещению капитала в общественно менее ценные, но зато более мобильные и легче спасаемые формы. В этом случае развивается теневая экономика. В-третьих, в результате угрозы потоку доходов снижается ценность накопленного капитала (капитала как запаса). Если частная собственность зависит от выплаты взяток, тогда вымогаемая взятка может сравняться с полной ценностью собственности, а, следовательно, такая собственность утрачивает свою ценность. В-четвертых, процесс извлечения ренты сопровождается значительными трансакционными издержками. И в-пятых, в общественные потери должны включаться и безвозвратные издержки, связанные с сокрытием капитала как объекта потенциального вымогательства со стороны политиков. Например, разработка и реализация схем утечки капитала сами по себе требуют достаточно больших затрат, в эту сферу вовлекаются значительные ресурсы» [24, pp.67-71].

\section{ВЫВОДЫ}

Теория “поиска ренты” тесно связана с теорией “групп интересов" (теорией “извлечения непроизводственного дохода"). В рамках теории “поиска ренты” есть два направления исследований.

Во-первых, это теоретический анализ и эмпирическое исследование, которое несет общество вследствие ограничений, вводимых государством для различных групп (монополия, тарифы и тд.). В данном контексте рассматривается группа, которая лоббирует вводимые ограничения и потери. При этом общество несёт потери за счет введения такого ограничения. Можно сделать вывод, что социальные потери от государственного вмешательства в экономическую сферу гораздо значительнее, чем предпологалось, так как к социальным потерям относится относят не только общим объеме потерь, но и издержки на конкуренцию между различными экономическими субъектами. Но когда к этим издержкам относят и издержки на информацию, то в совокупности они могут превысить ценность всего ресурса.

Во-вторых, изучение рентоориентированого поведения. Под ним понимается попытки индивидов увеличить свое благосостояние, за счёт уменьшения благосостояния остального общества. В рамках этого пункта необходимо изучить формирование бюрократии, а также неконкурентное поведения между фирмами и корпорациями. 
Теория “поиска ренты” - основная из групп интересов. Она учитывает социальные, политические факторы и группы интересов. При этом данная теория обладает недостатком - это роль государства в данном процессе. Государство рассматривается как совокупность различных групп интересов, которые в процессе конкурентной борьбы достигают равновесия на политическом поле и устанавливают те или иные права собственности (например, группа, проводящая интересы представителей естественных монополий; группа, представляющая интересы крупных производителей; и т.п.). Но, когда влияние государства ослабевает, то возникающее в теории “поиска ренты" распределение прав собственности совпадет с распределением всех других прав.

\section{ЛИТЕРАТУРА}

1. Фишер С., Дорнбуш Р., Шмалензи Р. Экономика. М.: Дело ЛТД, 1993.

2. Rutheford D. Routledge Dictionary of Economics. L \& N.Y.: Routledge, 1995.

3. Tollison R. Rent-Seeking: A Survey // Kyklos. 1982. Vol.35 (4).

4. Buchanan J.M. Rent Seeking and Profit Seeking // Toward a Theory of the Rent Seeking Society. College Station: Texas A\&M University Press, 1980.

5. Tullock G. The Economics of Special Privilege and Rent Seeking, Boston \& Dordrecht, Netherlands: Kluwer Academic Publishers 1989.

6. Tullock G. Rent Seeking as a Negative-Sum Game // Toward a Theory of the Rent Seeking Society. College Station: Texas A\&M University Press, 1982.

7. Tollison, Robert D. (1987). Is The Theory of Rent-Seeking Here to Stay? In Charles K. Rowley (ed.): Democracy and Public Choice: Essays in Honour of Gordon Tullock; pp. 143-57, Basil Blackwell, Oxford 1987. P. 145.

8. Хиллман А.Х. Западноэкономические теории и переход от социализма к рыночной экономике. Перспективы общественного выбора // Экономика и математические методы. 1996. Т. 32 (4).

9. Cowling K., Mueller D. The Social Costs of Monopoly Power // The Economic Journal. 1978. Vol. 88 (3).

10. Мюллер Д. Общественный выбор ІІІ / Пер. с англ. под ред. А. П. Заостровцева, А. С. Скоробогатова; Гос. ун-т - Высшая школа экономики, Институт «Экономическая школа». - М. 2007. - XIV+994 с.

11. Colander D. Some Simple Geometry of the Welfare Loss from Competitive Monopolies // Public Choice. 1985. Vol. 45 (2). 
12. Tollison R. Rent seeking // Perspectives on Public Choice: A Handbook. Cambridge, U.K., Cambridge University Press, 1997.

13. Buchanan J.M. Rent-Seeking, Non-Compensated Transfers, and Laws of Succession // Journal of Law and Economics. 1983. Vol. 26 (1).

14. Экономика, организация и менеджмент, в 2 т., Спб., 1999, т.1.

15. Brooks M., Heijdra B., Lowenberg A. Productive Versus Unproductive Labor and Rent Seeking: Lessons from History//Journal of Institutional and Theoretical Economics. 1990. Vol. 146 (3).

16. Rowley, Charles K. "Rent Seeking Versus Directly Unproductive Profit-Seeking Activities," in Charles K. Rowley, Robert D. Tollison and Gordon Tullock, The Political Economy of Rent Seeking (Boston: Kluwer Academic Publishers, 1988.

17. Sisk D. Rent Seeking: Non-compensated Transfers and Laws of Succession: A Property Rights View // Public Choice. 1985. Vol. 46 (1).

18. Институциональная экономика: новая институциональная экономическая теория / Под ред. А.А. Аузана. М., 2005.

19. Buchanan J.M. How Can Constitutions Be Designed so that Politicians Who Seek to Serve «Public Interest» Can Survive? // Constitutional Political Economy. 1993, vol. 4 (1).

20. Dean J. Kotlowski. Paul V. McNutt and the Age of FDR. Hardcover - January 2, 2015.

21. McNutt P. The Economics of Public Choice. Cheltenham, 1996.

22. Diermeier D., Ericson J., Frye T., Lewis S.. Credible Commitment and Property Rights: The Role of Strategic Interaction Between Political and Economic Actors // The Political Economy of Property Rights / D. Weimer (ed.). Cambridge, 1997.

23. Tullock, G., «The Welfare Costs off Tariffs, Monopolies. And Theft». Western Economic Journal 5 (1967).

24. Tullock, G., "Corruption and Anarchy," in Gordon Tullock (ed.), Further Explorations in the Theory of Anarchy (Blacksburg, Va.: Center for Study of Public Choice, 1974).

Статья поступила в редакцию 24 ноября 2016 года. 